University of Nebraska - Lincoln

DigitalCommons@University of Nebraska - Lincoln

Faculty Publications, Department of Physics and Astronomy

Research Papers in Physics and Astronomy

2014

\title{
LASER-WAKEFIELD ELECTRON ACCELERATOR WITH INDEPENDENT BEAM-PARAMETER CONTROL
}

\author{
Grigory V. Golovin \\ University of Nebraska-Lincoln, ggolovin2@unl.edu \\ Shouyuan Chen \\ University of Nebraska-Lincoln, schen6@unl.edu \\ Nathan D. Powers \\ University of Nebraska-Lincoln, ndp5@byu.edu \\ Cheng Liu \\ University of Nebraska-Lincoln, cliu8@unl.edu \\ Sudeep Banerjee \\ University of Nebraska-Lincoln, Sudeep.Banerjee@asu.edu
}

See next page for additional authors

Follow this and additional works at: https://digitalcommons.unl.edu/physicsfacpub

Golovin, Grigory V.; Chen, Shouyuan; Powers, Nathan D.; Liu, Cheng; Banerjee, Sudeep; Zhang, J.; Zeng, M.; Sheng, Z.; and Umstadter, Donald, "LASER-WAKEFIELD ELECTRON ACCELERATOR WITH INDEPENDENT BEAM-PARAMETER CONTROL" (2014). Faculty Publications, Department of Physics and Astronomy. 147. https://digitalcommons.unl.edu/physicsfacpub/147

This Article is brought to you for free and open access by the Research Papers in Physics and Astronomy at DigitalCommons@University of Nebraska - Lincoln. It has been accepted for inclusion in Faculty Publications, Department of Physics and Astronomy by an authorized administrator of DigitalCommons@University of Nebraska - Lincoln. 
Authors

Grigory V. Golovin, Shouyuan Chen, Nathan D. Powers, Cheng Liu, Sudeep Banerjee, J. Zhang, M. Zeng, Z. Sheng, and Donald Umstadter 
Plasma Sciences (ICOPS) held with 2014 IEEE International Conference on High-

Power Particle Beams (BEAMS), 2014 IEEE 41st International Conference on

Year: 2014

Pages: 1 - 1, DOI: 10.1109/PLASMA.2014.7012361

\title{
LASER-WAKEFIELD ELECTRON ACCELERATOR WITH INDEPENDENT BEAM-PARAMETER CONTROL
}

\author{
G. Golovin, S. Chen, N. Powers, C. Liu, S. Banerjee, \\ J. Zhang, M. Zeng, ${ }^{1}$ Z. Sheng, ${ }^{1}$ and D. Umstadter \\ University of Nebraska-Lincoln, Physics and Astronomy \\ Department, Lincoln, NE 68508, USA
}

It has been demonstrated that laser-wakefield acceleration (LWFA) can generate several electron beam parameters rivaling those generated by conventional RF-cavity accelerators. Tunable and monoenergetic electron beams have also been produced with LWFA. Currently, active research is being directed towards finding methods to generate $e$-beams that have independently controllable parameters, as is standard in the case of conventional accelerators. One promising approach is to separate and independently control the essential acceleration processes. ${ }^{2}$

We report demonstration of such control with LWFA, by usage of a single laser pulse (33-fs duration, 1.7-J energy) and optimized plasma profiles, of density and atomic composition. As a result, we were able to generate stable, quasi-monoenergetic electron beams, and tune their central energy over the 50-140 MeV range, while preserving both their quality, charge (20 pC), and absolute energy spread (15 $\mathrm{MeV})$. We also demonstrated the scalability of this approach, by independently increasing the acceleration length, and boosting the maximum central energy to $450 \mathrm{MeV}$.

The plasma profiles of the acceleration medium consisted of three distinct regions. In the first, the laser pulse evolved, self-focused, and formed an acceleration bubble. In the second, electrons were injected in the bubble via ionizationassisted injection. In the third region, electrons were accelerated by a laser wakefield, and the bunch underwent phase-space rotation. This seamless integration of electron injection and acceleration resulted in injection of electrons into acceleration bucket in the correct phase, utilizing the full length of accelerating field, and eliminating the problems associated with external synchronization.

The beam-parameter control that was enabled by this approach recently proved essential to the success of a novel source of quasi-monoenergetic and tunable x-rays, generated through LWFA and inverse Compton scattering. ${ }^{3}$

\footnotetext{
${ }^{1}$ Shanghai Jiao Tong University, Laboratory for Laser Plasmas, Shanghai 200240, China
}

${ }^{2}$ S. M. Hooker, Nat. Photon. 7, 775 (2013)

${ }^{3}$ N. Powers et al., Nat. Photon. 8, 28 (2014) 